of the Far-San Archipelago are superficially very diverse, but are all remarkable for the extreme steepness of their sides, which descend in a series of almost vertical cliffs separated by narrow platforms. The distribution of organisms on the reefs is dependent upon the turbulence of the water, the intensity of illumination, the depth, and the slope of the sides. The physical conformation of the reefs, and the existence of a submarine cliff $650 \mathrm{~m}$. high, fit Darwin's theory of the formation of coral reefs by subsidence.

In his paper on marine bottom substrata and their fauna, Prof. C. M. Yonge (Glasgow) showed that the major factors influencing the distribution of bottom invertebrates are food and the nature of the sub. stratum. The main problem is the potential food value of the deposits, for detritus contains a hundred times more organic carbon than is contained in the total fauna and flora. Knowledge is urgently required about the nutritive value of detritus, and about the factors controlling its local concentration. Bottom associations cannot be regarded as consisting of interdependant organisms as are the members of associations on land. The carnivores depend upon the presence of the suspension- and deposit-feeders; but members of these are all competing for the same food and so would actually benefit if competitors were absent. In this connexion the paper by Prof. C. ZoBell (La Jolla, California) was of great interest; in it he discussed the occurrence of bacteria in the deep sea and their significance to animal life. It appears probable that they provide the first step in the chain of organic food substances at great depths.

But the communication of greatest general interest on marine biology was the lecture, illustrated by a colour film, given by Dr. Anton Bruun (Copenhagen) on the methods and results of the Galathea Expedition, 1950-52. The film showed all phases of the voyage, the object of which was to explore the greatest ocean depths, and it was a remarkable experience for most of the zoologists present to see close-up moving pictures of the extraordinary fishes and invertebrates as they were brought on deck from immense depths fresh and in their natural colours, and in many cases still alive. Many of the more striking specimens collected on the voyage were on exhibition in the University Museum, and the vessel herself was lying in the harbour.

A communication from Prof. C. Hubbs (La Jolla, California) gave news of one of the most interesting of the larger Cetacea, the Pacific grey whale, which had been very nearly exterminated by the early years of this century. It has lately made a great recovery in numbers, and as its migration route passes close inshore off La Jolla, the zoologists of the Scripps Institute have been able to make close observations on its numbers. The observations from land have been supplemented by surveys made over the sea and the lagoons of Lower California from a helicopter, and it has been ascertained that a population of many hundreds of the animals frequents these waters. The paper was illustrated by remarkable photographs of the whales taken at close range from the helicopter.

Other aspects of marine biology were discussed, among many others, in papers by G. P. Wells (London) on "Inherent Rhythms in the Behaviour of Worms", D. L. Ray (Washington) on the "Digestion of Wood by Limnia lignorum", and Prof. P.-H. Fischer (Vietnam) on "Gasteropodes Excavateurs de Roches littorales".

These communications are, however, no more than a random sample from the immense variety presented to this most interesting and stimulating Congress... a variety ranging from "Paper Chromatographic" Analysis of Taxonomic Relationships in Drosophila", "Polarized Light and Arthropod Vision", and the "Perception of Low-frequency Vibrations by Semotilus atromaculatus", to the "Display, Breeding Cycles and Phylogeny of Bower Birds", the "Influence of Spermatic Hormones on Spawning and Water Flow in the Oyster", and "Wirkungen der Epiphysectomie und der Epiphysolbehandlung bei Fischen".

The Danes are the most hospitable of hosts, and in addition to the scientific sessions they had prepared a very. full programme of excursions, receptions, dances and other social functions that were greatly enjoyed and appreciated by the members of the Congress-at the closing banquet a footnote on the menu, in which all the main ingredients of the dishes were given their scientific names, warned " $H \alpha c$ nomina sunt conservanda in spiritu vini", an echo of the deliberations of the International Committee on Nomenclature.

At the closing General Session of the Congress an invitation conveyed by Dr. E. Hindle from the Royal Society of London to hold the fifteenth International Congress of Zoology in London in 1958 was received with acclamation, and Dr. G. R. de Beer, director of the British Museum (Natural History), was elected to be its president. British zoologists will hope that the Government will place funds at the disposal of the organizers of the fifteenth Congress on a scale similar to the support afforded by the Danish Government to the fourteenth. L. HaRRISON MATTHEws

\section{ZOOLOGICAL NOMENCLATURE AMENDMENTS TO THE INTERNATIONAL CODE}

$T$ HE fourteenth International Congress of Zoology, Copenhagen, August 1953, carried through the second stage of the important and long overdue process of overhauling the International Code of Zoological Nomenclature, of which the first stage took place at the thirteenth congress held in Paris in 1948. The work on zoological nomenclature.at Copenhagen was path-breaking as regards both procedure and achievements, because the procedure was new and without it the achievement would not have been possible.

The procedure differed from that at any previous Congress in two essential respects: first, very elaborate measures were taken to provide the Congress in advance of its meeting with an ample documentation on all the nomenclatorial problems to be considered; second, arrangements were made for the careful consideration and full discussion of this material at a colloquium on zoological nomenclature which sat daily at Copenhagen for a week prior to the opening of the Congress. The preparations for this meeting consisted in the publication by the International Trust for Zoological Nomenclature early in 1952 of a special volume (vol. 7) of the Bulletin of Zoological Nomenclature containing a discussion of the major problems of zoological nomenclature which had been remitted by the Paris Congress for further study and for consideration five years later at Copenhagen. This volume was communicated by the Trust to museum nomenclature committees and leading zoological and palæontological institutions and served to secure for the Copenhagen 
Congress a large and representative range of comment on the difficult problems involved. Later--in 1953these comments, together with the documentation relating to other items on the Copenhagen agenda, were published by the Trust in two special volumes (vols. 8 and 10) of the Bulletin. In March of this year the Trust issued invitations both to institutions and organizations concerned with systematic zoology (including palæozoology) to appoint representatives to the colloquium. In addition, personal invitations were issued to the members of the International Commission on Zoological Nomenclature and to other specialists known to be interested in nomenclature. When the colloquium opened on July 29 , it numbered more than fifty members drawn in almost equal numbers from the Old World and the New. Sixteen meetings were held by the colloquium before the opening of the Congress, and the full and detailed discussions held made it possible to reach agreement upon recommendations to be submitted on all except one of the seventy items on the agenda. Some of the problems involved were of great complexity and might well have led to sharp disagreement, if it had not been for the general desire of all the members of the colloquium to achieve solutions which were both the best obtainable in the circumstances and in addition commanded the general support of interested zoologists.

A further important and novel feature of the procedure adopted at Copenhagen was the clear recognition for the first time of the essential difference between the advisory functions of the International Commission on Zoological Nomenclature in the legislative field and the strictly judicial functions of that body. At Copenhagen -unlike at previous congresses--there was no discussion of individual cases, which it was recognized could be dealt with better by the Commission by means of postal votes. The whole of the time available was thus devoted by the Commission, the Colloquium and the Section on Nomenclature of the Congress to the reform of the code. This procedure possesses the great merit that it recognizes that it is vital that reforms of the code should command the widest possible support of zoologists generally and that, to secure this end, extensive and representative consultations, followed by full discussion, are essential. The practical value of this procedure is attested by the fact that it made it possible to submit to the Congress a comprehensive report on the whole range of problems considered.

The first and most important single subject dealt with was how to provide means for ensuring that zoological nomenclature shall be both stable and universally accepted. The attainment of this object was sought by a number of means : (a) the addition to the code of a preamble stressing that the forogoing were the objects for which it had been established; (b) the introduction of machinery for the disposal of the threat to stability represented by dormant nomina dubia; (c) the recognition (by a majority vote) of the principle of conservation under which, subject to certain safeguards, a junior synonym which has been in general use for a considerable period will be protected from being replaced by a senior synonym which is virtually unknown and has scarcely ever been used; $(d)$ the addition of provisions for restricting and designating type localities for nominal species where those given by the original author were either too vague or incorrect. The second addition to the code of great importance was the introduction of provisions for the recognition, subject to strict safeguards, of neotypes as a category of type specimen in cases where the original type material is lost and definite identification is impossible without detailed examiruation of the structure of a specimen serving as a unique standard of reference.

Next, the Congress introduced a comprehensive series of rules for the naming of taxa belonging to the family-group of categories in place of the wholly inadequate provisions (Articles 4 and 5) in the present code. At the same time, the Congress introduced provisions for regulating the naming of orders, classes and phyla, the one field in which hitherto the code had possessed no provisions and in which the utmost instability and confusion prevails. Under these provisions, names belonging to these groups, like names for all lower categories, will be defined by the type method. The selection of names for units already established in these categories will be made by committees of specialists in the groups concerned, and an opportunity for comments by specialists will be provided before the names recommended by the committees are finally approved by the International Commission and placed on the "Official Lists" established for this purpose by the Congress. Next, the Congress completely overhauled the provisions (Article 19) relating to the emendation of names, wiping away the ambiguities which in the past have led to much confusion and greatly reducing the area within which emendations will be permissible, niceties of etymology and the like no longer constituting a valid ground for emending a name.

Having thus disposed of the major problems referred to it by the Paris (1948) Congress, the Copenhagen Congress dealt also with the large mass of problems which have been brought forward since the Paris Congress. Of these, the following call for special mention: (1) the withdrawal, subject to safeguards in the interests of current practice, of recognition from names first published in synonymies; (2) the introduction of words designed to ensure that for a specific name published subsequent to December 31,1930 , to acquire availability its author must have attempted to indicate the characters relied upon by him as diagnostic for the unit named ; (3) the banning of the distribution of microfilms, microcards and the like as a method of 'publishing' zoological names; (4) the reversal of the Paris decision to substitute the page precedence principle for that of the First Reviser for determining the relative precedence to be assigned to names published in the same book and on the same date ; $(5)$ the introduction of provisions to prevent the wanton invalidation of specific names as junior secondary homonyms by unions of genera regarded as unjustified taxonomically by specialists in the groups concerned.

Many of the provisions introduced at Copenhagen are marked by a provision of a novel character designed to enable systematists, wherever possible, to take advantage of the means afforded for ensuring stability without having to submit every case individually to the International Commission. By this method, specialists are required to act on the provisions in question immediately upon the appearance in the Bulletin of Zoological Nomenclature of a notification of the publication by an author of a paper in which he has taken advantage of the provision concerned. Within specified periods, such action is open to challenge and, if so challenged, the case is to be referred to the Commission for decision. In other cases, the action taken becomes definitive at the end of the prescribed period and the name 
concerned is placed on the appropriate "Official List" of valid names or on the appropriate "Official Index" of rejected names. This procedure, while of great convenience to systematists, inevitably throws a greatly increased burden of work upon the secretariat of the International Commission and, through the increase in the amount of material to be published in the Bulletin of Zoological Nomenclature, will increase still further the financial difficulties of the International Trust for Zoological Nomenclature, the incorporated body which conducts the business affairs of the (unincorporated) International Commission. So serious, indeed, are the difficulties of the Trustwhich possesses no income other than that obtainable from the sale of its publications-that the Right Hon. Walter Elliot, chairman of the Trust, paid a special visit to Copenhagen for the express purpose of warning the zoologists and palæontologists there assembled-and, through them, the great scientific institutions in which they work-that it would be impossible for the Trust to continue to maintain the work of the Commission unless a scheme were to be devised for providing the annual income essential for this purpose.

During the Congress, the colloquium drew up a report setting out in detail the recommendations for the reform of the code which it had adopted in the week preceding the opening of the Congress, and this report was discussed in draft both with the International Commission on Zoological Nomenclature and with the Section on Nomenclature of the Congress. As the result of these discussions, the report of the colloquium was submitted jointly by both these bodies to the Copenhagen Congress, by which it was unanimously adopted at the final Concilium Plenum. The report of the colloquium accordingly constitutes the official record of the decisions on nomenclature taken by the Copenhagen Congress, and, as such, will be an indispensable work of reference to all systematists until such time as it is possible, on the basis of the Paris (1948) and Copenhagen (1953) decisions, to prepare and promulgate a revised text of the code. In agreement with the Congress and at its request, the International Trust for Zoological Nomenclature is publishing the report of the colloquium in book form. In order to bring this work within the reach of every zoologist, the Trust is subsidizing this publication to an extent sufficient to enable it to be placed on sale for five shillings (75 U.S. cents); copies will be obtainable from the offices of the Trust (41 Queen's Gate, London, S.W.7). It is expected that publication will take place towards the end of November. Francis Hemming

\section{CHEMICAL RESEARCH LABORATORY, TEDDINGTON OPEN DAYS}

$\mathrm{T}$ HE annual open days of the Chemical Research Laboratory, Teddington, were held this year during September 22-25. A feature of the previous year was the new building provided for radiochemical work, and this year another new laboratory was open for inspection. This was a building of prefabricated type but specially fitted for microbiological research. It has a floor space of about 3,000 sq. ft. and contains five research rooms, an instrument room, a small library, a general fermentation laboratory with cold and warm chambers, and a 'kitchen' for the preparation and sterilization of media and glassware. The design is such that the risk of contamination of cultures is brought to a minimum. The air is filtered before entry, sliding doors are provided to prevent draughts, and the walls and floors are finished to allow easy cleaning. This building was occupied during November 1952.

The main topic of the Microbiology Group is the fundamental study of the metabolism of sulphatereducing bacteria. Interesting exhibits related to the counting of these bacteria, and a demonstration was given of the presence of cytochromes detected for the first time in anaerobic bacteria. The production of sulphide and methane by anaerobic digestion of sewage sludge supplemented with sulphate was demonstrated. Another exhibit illustrated the breakdown of aromatic compounds by bacteria isolated from filter beds in which effluents from chemical works are rendered innocuous. An important section of the Group is the National Collection of Industrial Bacteria. The primary purpose of the Collection is to supply on request cultures of bacteria required by industry and research establishments, and some seven hundred cultures were sent out during 1952 to organizations all over the world. The Collection now maintains nearly six hundred strains of bacteria, as well as several antibiotic-producing organisms deposited by the United Nations World Health Organization. Research is being carried out on the effect of freeze-drying on the biochemical characteristics and viability of the cultures.

Earlier work of the Laboratory's Inorganic Group revealed that certain flue dusts provide a concentrated source of germanium and gallium, and the dusts are now being used commercially for the production of these elements. A new extension of the work on the recovery of valuable products from wastes or low-grade materials is a search for selenium in dusts and sludges arising in the purification of the sulphur dioxide produced by the burning of pyrites in the new flash-roaster plants. In most of the dusts the selenium content is small, ranging from 10 to 100 parts per million; but in one type of sludge the amount rises to $1-2$ per cent, while in another type, three samples of which were shown during the open days, the content varies from 7 to 21 per cent on a dry basis. If these sludges occur in sufficient quantity, they may prove to be a useful source of this increasingly important element. In addition to pure germanium and gallium prepared in the laboratory, samples of twenty other metals in a high state of purity were exhibited, the most striking of these being titanium prepared by the van Arkel process. These metals form part of the stock held by the Pure Metals Committee of the Department of Scientific and Industrial Research.

The Inorganic Group is also responsible for microchemical and spectrographic analyses required either by the Laboratory or other stations of the Department. The sections concerned are well equipped with modern apparatus, and the expert teams are prepared to give advice on the applications of these instruments.

The exhibits in the Radiochemical Group were largely concerned with separation techniques for metals and acid radicals, with particular emphasis on chromatography and ion exchange. Of special interest in chromatography is the development of this process to geochemical prospecting by a simple and rapid method for use in the field. Extracts of the mineral samples under study are obtained usually by simple 